\title{
An ANN-Based Approach for Lightning-Caused VFT Detection in GIS
}

\author{
Ebrahim A. Badran ${ }^{*}$, , Mohammad H. Abdelrahem ${ }^{2}$ and Mansour H. Abdel-Rahman ${ }^{1}$ \\ ${ }^{I}$ Electrical Engineering Department, Mansoura University, Mansoura, Egypt \\ ${ }^{2}$ Middle Delta Electricity Generation Company, Talkha, Egypt
}

\begin{abstract}
This paper introduces an artificial neural network (ANN) approach for the detection and identification of lightning-caused very fast transient (VFT) in gas insulated substation (GIS). VFT in GIS can be due to faults, lightning and switching operations. VFT in GIS has to be located and classified as soon as possible to start the processes of reconfiguration and restoration of the normal power supply. A practical case study is investigated in Talkha $220-\mathrm{kV}$ GIS which represents a critical generation point in the Egyptian Electric Power Network. The layout of the Talkha 220-kV GIS is discussed and modeled using ATP/EMTP. The ANN-based approach is built and trained. Finally, the proposed approach is tested using bolt ground faults, high impedance faults, and lightning on the connected transmission lines. The results ensure the success of the proposed approach to classify and discriminate the faults and the lightning-caused VFT.
\end{abstract}

Keywords: GIS, Lightning, VFT, Fault, ANN, ATP/EMTP.

\section{INTRODUCTION}

In power system substations, faults that produced load disconnections or emergency situations have to be located as soon as possible. Faults location is necessary to start the substation reconfiguration for restoring normal energy supply. Failures in GIS are known to have occurred both during early years of operation and during site testing or assembling. From the statistical point of view, problems have occurred at the highest voltage levels rather than the lower level [1]. However, the identification of the faulted points is not always an easy task, delaying the restoration procedures. This usually occurs when the protection system does not behave as expected. Substation in commissioning phase or even the ones already in operation, but with complex constructive and operational natures, can have high indices of protection system failure. In these substations, fault location can take a long time due to the great amount of information to be analyzed. The difficulty in identifying the fault points significantly increases in non-conventional substation, as gas-insulated ones [2].

In GIS a large number of restrikes occur across the switching contacts when disconnector, breaker operations, the closing of grounding switch, and by line-to-ground faults. Each strike leads to generation of VFT [2]. The generation and propagation of VFT from their original location throughout a GIS can produce internal and external overvoltages. In case of a line-to-ground fault, the voltage collapse at the fault location occurs in a similar way as in the disconnector gap during striking. Step-shaped traveling surges are generated and injected to GIS lines connected to the collapse location [3].

*Address correspondence to this author at the Electrical Engineering Department, Mansoura University, Mansoura, Egypt;

Tel: +2-011-11109383; Fax: +2-057-2402865;

E-mail: ebadran@mans.edu.eg.
VFT in GIS can be divided into internal and external. Internal transients can produce overvoltages between inner conductors and the encapsulation. External transients can cause stress on secondary and adjacent equipment. Breakdown phenomena across the contacts of a disconnector during a switch operation or line-to-ground faults generate very short rise time traveling waves which propagate in either direction from the breakdown or fault location. Surges traveling throughout GIS and to other connected equipment are reflected and refracted at every transition point. As a consequence of multiple reflections and refractions, traveling voltages can increase above the original values and very high frequency oscillations occur. An internally generated VFT propagates throughout the GIS and reaches the bushing where it causes a transient enclosure voltage and a traveling wave that propagates along the overhead transmission line [2].

In the areas of power systems, problems may have one or more of the following characteristics: dynamic, non-linear, large scale and random like. These factors make power system problems more difficult to solve. Therefore, computers are extensively applied to power system operation, planning, monitoring and control. Current approaches to power system computation are mainly based either on developing a mathematical model of a relevant part of the system or on expert systems. Artificial Neural Networks (ANNs) provide a promising and attractive alternative [4].

ANNs have the inherent capacity of modeling functional relationships between input and output data without the explicit knowledge of an analytical model. ANNs have a great pattern recognition capabilities and their ability to handle noisy data. There are widespread applications of ANNs in a number of different areas of power systems such as: load forecasting, security assessment, control, system identification, protection, fault location, adaptive auto reclosing, operational planning, etc. Matlab/Simulink has a 
suite of programs designed to build ANNs (Neural Networks Toolbox) [5]. There are three steps to using ANNs; design, training, and testing $[6,7]$.

This paper concerns the lightning-caused VFT and the fault identification and detection in GIS. A practical case study is analyzed using Talkha $220-\mathrm{kV}$ GIS. This GIS represents a critical generation point in the Egyptian Electric Power Network. The layout of the Talkha $220-\mathrm{kV}$ GIS is discussed and modeled using ATP/EMTP. The ANN-based approach is built and trained. The proposed approach is tested using solidly ground faults, high impedance faults, and lightning on the connected transmission lines.

\section{MODELING OF TALKHA 220-KV GIS}

\subsection{GIS Layout}

Talkha $220 \mathrm{kV}$ GIS is an important generation busbar in the north of Egypt. The fault in GIS at this point in the Egyptian power network may lead to severe stability events that may result in a complete or partial blackout. So, attention must be given to prevent or limit fault consequences. A typical $220 \mathrm{kV}$ GIS installation of a one- and-half circuit breaker arrangement is used in this paper as a case study. It consists of circuit breakers, disconnectors, busbars, surge arresters, transmission lines, transformers, generators, coupling feeders, earthing switches.

Fig. (1) illustrates the construction of Talkha $220 \mathrm{kV}$ GIS. It consists of eight bays; each with three circuit breakers, six disconectors, six current transformers, and eight earthing switches. The GIS system contains two busbars which are supplied from seven generation sources using two $150 \mathrm{MVA}$ delta/star $11.5 / 220 \mathrm{kV}$ transformers, two 200 MVA star/star $11.5 / 220 \mathrm{kV}$ transformers, and three 320 MVA delta/star $16.5 / 220 \mathrm{kV}$ transformers which supplies a $66 \mathrm{kV}$ substation through five $125 \mathrm{MVA}, 220 / 70 \mathrm{kV}$ star/star transformers, and six transmission lines which connect the GIS to the surrounding substations.

\subsection{GIS Modeling}

Due to the traveling wave nature of the VFT, the GIS elements are modeled as electrical equivalent circuits composed of distributed parameter lines (defined by surge impedance and traveling times) as well as lumped elements. In order to achieve reliable simulation results the GIS is

BB\#1 220kV

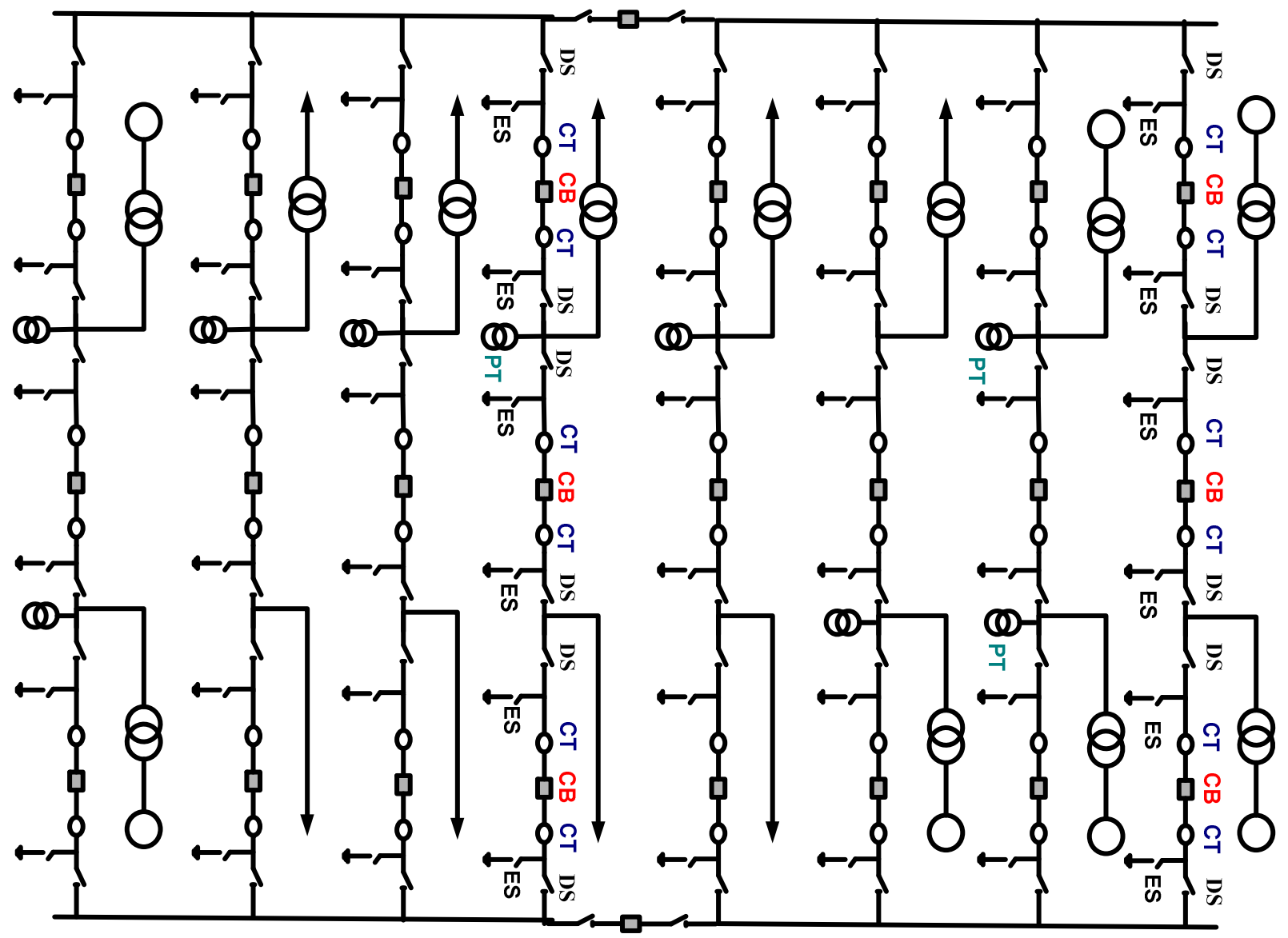

BB\#2 220kV

Fig. (1). A typical single line diagram of Talkha 220-kV GIS. 
Table 1. Models of GIS Components

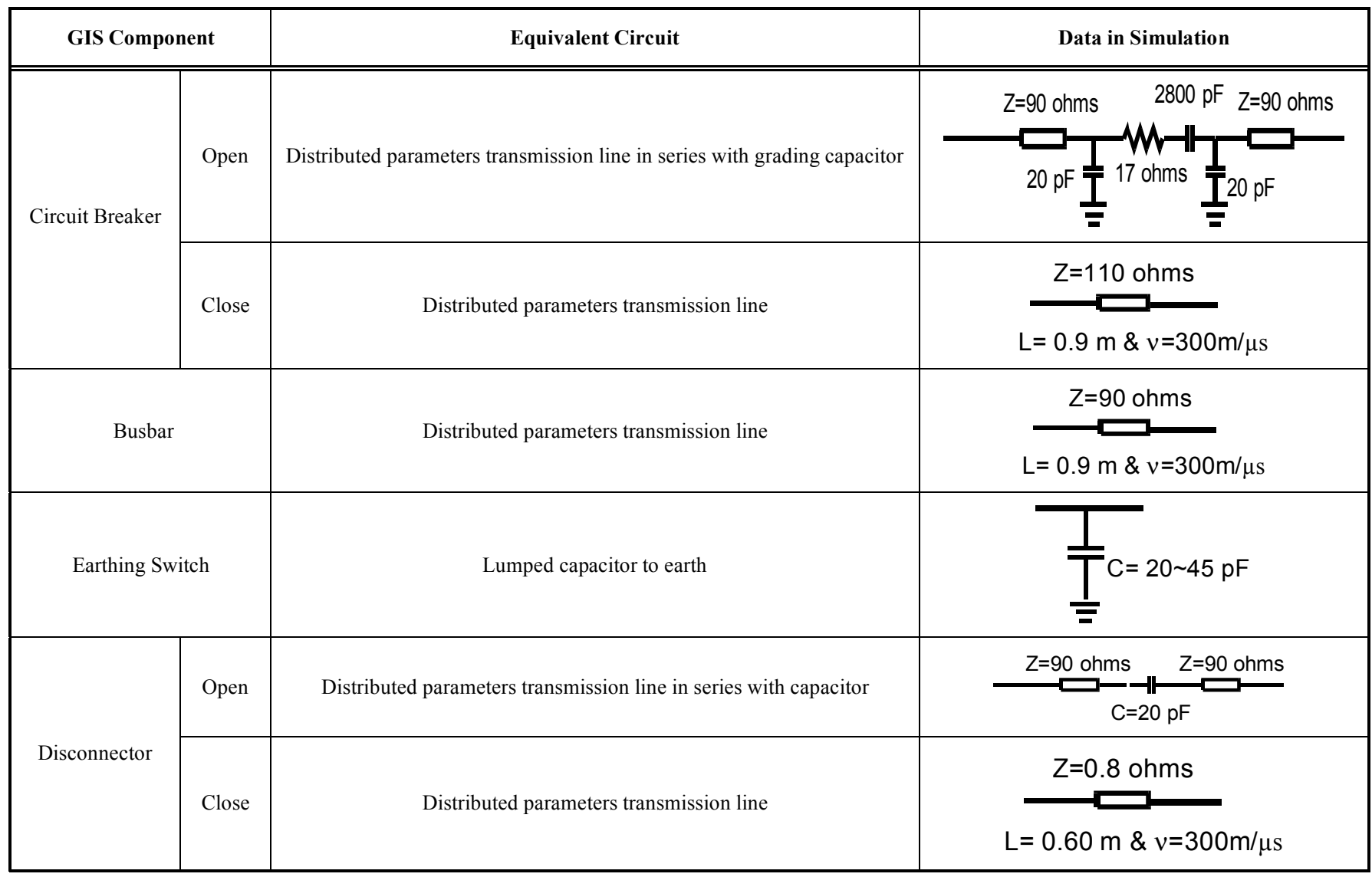

subdivided into several shorter sections. Table $\mathbf{1}$ gives the GIS components and how to be modeled $[2,8]$.

The GIS installation is regarded as series of distributed parameters transmission lines and lumped capacitor elements. The parameters of each GIS section are calculated from the standard formula of capacitance. The capacitance is calculated with the assumption that the conductors are cylindrical [9]. Capacitance is calculated by the following [3, 10];

$$
\mathrm{C}=2 \pi \varepsilon_{\mathrm{o}} \varepsilon_{r} l / 2.3 \ln (\mathrm{b} / \mathrm{a})
$$

where $b$ is the outer cylinder radius, $a$ is the inner cylinder radius, and $l$ is the length of the section.

Spacers are used for supporting the inner conductor with reference to the outer enclosure. They are made with Alumina filled epoxy material whose relative permittivity, $\varepsilon_{\mathrm{r}}$, is 4 . The thickness of the spacer is assumed to be the length of the capacitor which is taken as $15 \sim 1000 \mathrm{pF}$.

The busbar is represented by the surge impedance, the velocity of surge propagation, and the length. The surge impedance of the busbar is calculated from the relation [9];

$\mathrm{Z}=60 \times \ln (B / A)$

where $\mathrm{A}$ is the diameter of the bus and $\mathrm{B}$ is the inner diameter of the enclosure. The surge impedance of the 220$\mathrm{kV}$ busbar is taken as $90 \Omega$ and the surge velocity is assumed be the velocity of light.
Fig. (2) illustrates the ATP/EMTP model of Talkha 220$\mathrm{kV}$ GIS. In this model each Bay consists of three partitions and each partition has six sections. So the fault can be applied at eighteen points for each Bay in the GIS.

The surge arrester is modeled by the frequency dependent model introduced in [11-13] shown in Fig. (3). The inductances $\mathrm{L}_{0}$ and $\mathrm{L}_{1}$ characterize the frequency dependence of the surge arrester, with respect to the lightning current surges, which are determined by the following relations $[11,14]$ :

$\mathrm{L} 0=0.01 * \mathrm{~V}_{\mathrm{n}} \quad \& \mathrm{~L} 1=0.03 * \mathrm{~V}_{\mathrm{n}}$

where $V_{n}$ is the rated voltage of surge arrester. The input resistance $R_{0}$ is implemented for numerical stability and its value is equal $1 \mathrm{M} \Omega$ [12]. A0 and A1 are non-linear resistors that represent the non-linear V-I characteristic of the model [12]. Fig. (4) shows the V-I characteristic [15]. The nonlinearities, A0 and A1, are modeled in ATP/EMTP using non-linear resistor (type-92) [12, 13, 16].

\subsection{Simulation of Faults and Lightning}

Faults in GIS are modeled using single-line-to-ground fault with two types; solidly to ground (SLG) and high impedance fault (HIF). The arc of the HIF is based on the energy balance of the arc and describes an arc in air by a differential equation of the arc conductance (g) [17]. Fig. (5) illustrates the main components of the HIF arc model using ATP/EMTP [18]. 


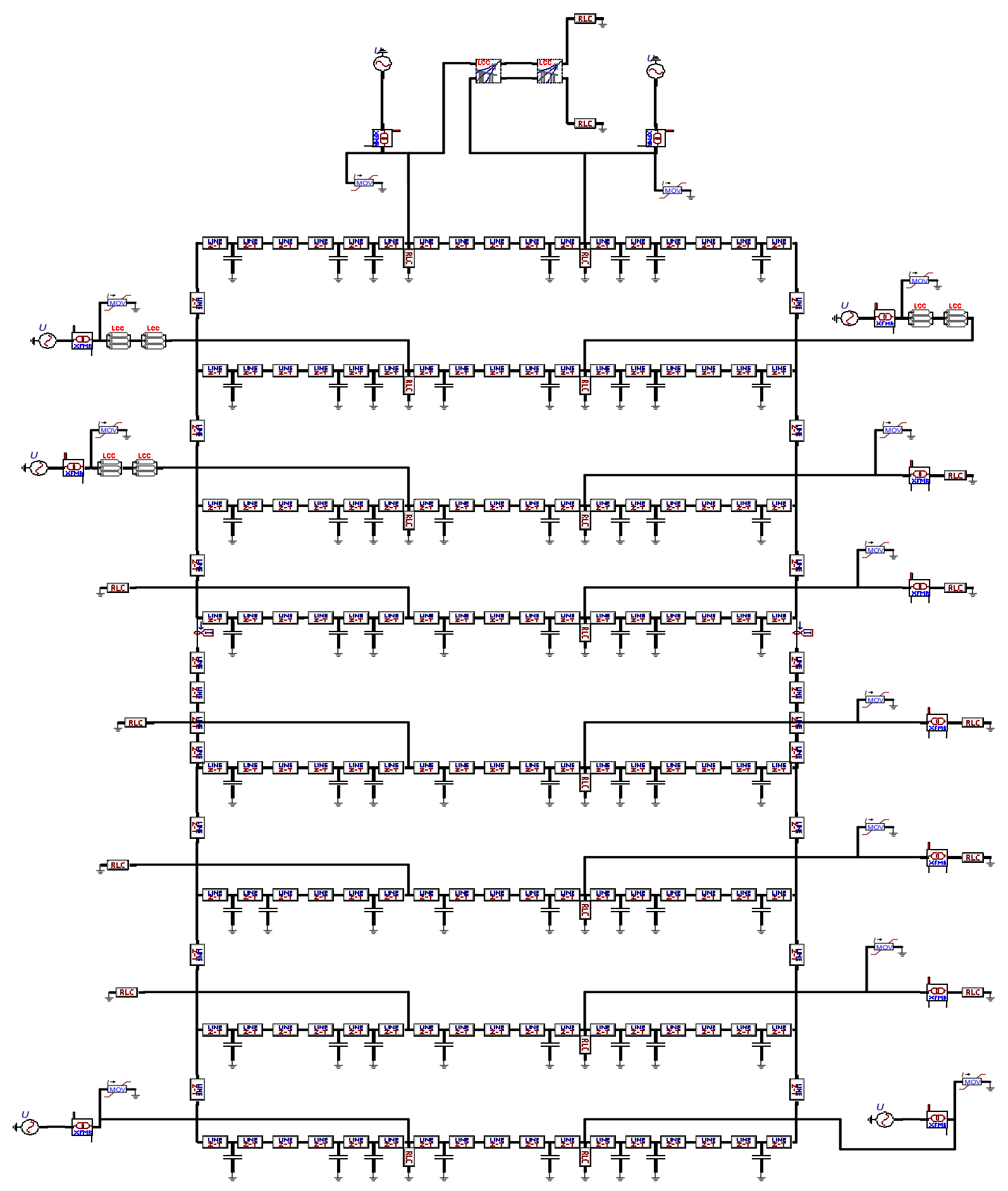

Fig. (2). ATP/EMTP model of Talkha 220-kV GIS.

Fig. (6) shows the single-line diagram of Bay\#1 and the fault scenarios at three points; node 1 , node 2 , and node 3 , respectively. Fig. (7) illustrates the current waveforms of phase A of BB\#1 for SLG in Bay\#1 and Bay\#7. Fig. (8) illustrates the current waveforms of phase $A$ of $B B \# 1$ for HIF in Bay\#1 and Bay\#7. 


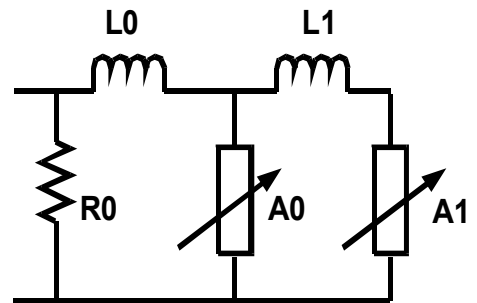

Fig. (3). Simplified IEEE model (Pinceti-Giannettoni Model).

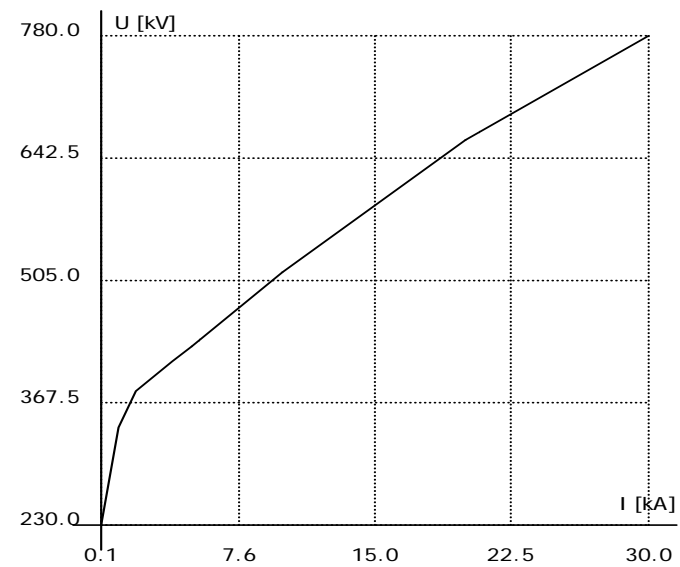

Fig. (4). The current/voltage characteristics of the surge arrestor.

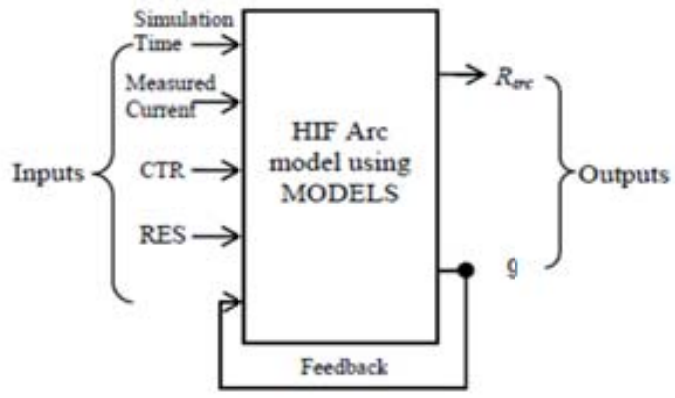

Fig. (5). ATP/EMTP HIF Arc Model.

The current is measured at the middle of $\mathrm{BB} \# 1$ near the bus-tie. The most of generation units are located in the upper part of GIS; as shown in Fig. (2). It is noted that for the fault on Bay\#7, all the generation units feed this fault, so the monitored fault current at the measuring point at the middle of BB\#1 for both HIF and SLG is greater than that measured for Bay\#1.

Table 2 summarized the maximum monitored fault currents at different fault scenarios. It is clearly seen that the closer the fault points to the monitoring point, the higher the absolute peak of the monitoring fault currents.

Table 2. Absolute Peak of the Monitoring Fault Current for Fault Scenarios

\begin{tabular}{|c|c|c|c|}
\hline \multicolumn{2}{|c|}{ Fault } & \multicolumn{2}{c|}{ Absolute Peak of the Fault Current (A) } \\
\cline { 3 - 4 } \multicolumn{2}{|c|}{} & SLG & HIF \\
\hline \hline \multirow{2}{*}{ \# } & node1 & 4492 & 8 \\
\cline { 2 - 4 } & node2 & 4669 & 17 \\
\cline { 2 - 4 } & node3 & 6416 & 92 \\
\hline \multirow{2}{*}{ 蓄 } & node1 & 12648 & 29 \\
\cline { 2 - 4 } & node2 & 13049 & 35 \\
\cline { 2 - 4 } & node3 & 15767 & 115 \\
\hline
\end{tabular}

Lightning is simulated as an impulse current source of 51 $\mathrm{kA}$ in parallel with a resistance of $400 \Omega$ [19]. Fig. (9) shows a double circuit transmission lines which are connected to the GIS; Line\#1 and Line\#2. Each of them is $10 \mathrm{~km}$ length. The lightning is applied at different points along the two lines. Figs. $(10,11)$ illustrate the current waveforms of phase A of BB\#1 for lightning applied on Line\#1 and Line\#2, respectively, at different points.

\section{THE PROPOSED ANN-BASED CLASSIFIER}

ANN have demonstrated the special capability of mapping the very complicated relationships between the inputs and the outputs and of revealing subtle differences in features between ill-defined patterns, particularly of the aforementioned types associated with wideband fault generated noise

A large number of simulations are performed to generate a good representative data set for training and testing ANN. Once sets of training/testing patterns have been generated, the appropriate ANN architecture and associated parameters are chosen. The task of ANN is to learn to capture the VFT in GIS and detect the reason and its location.

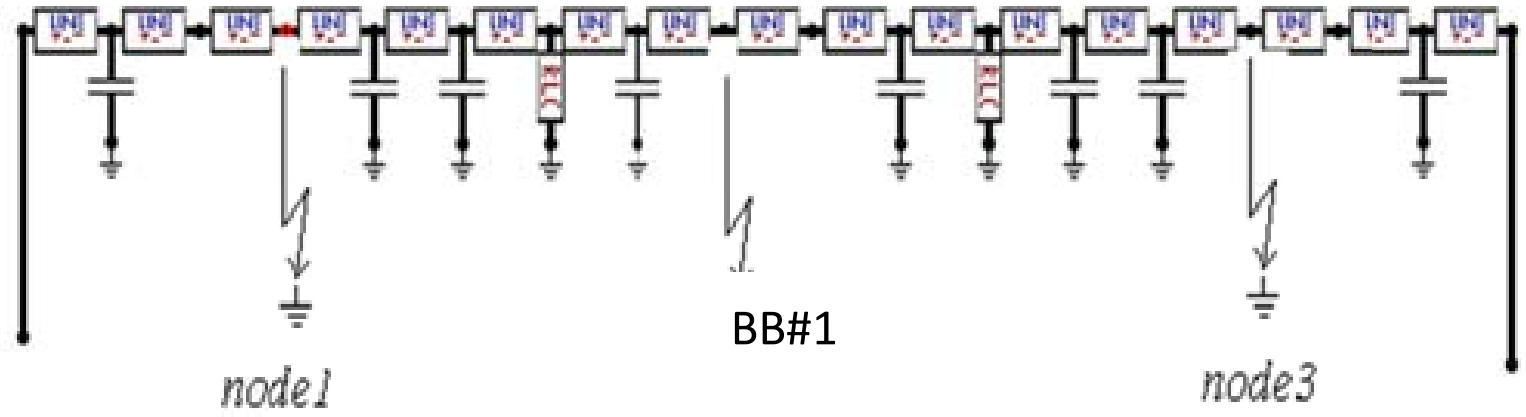

Fig. (6). Fault scenarios at Bay\#1. 

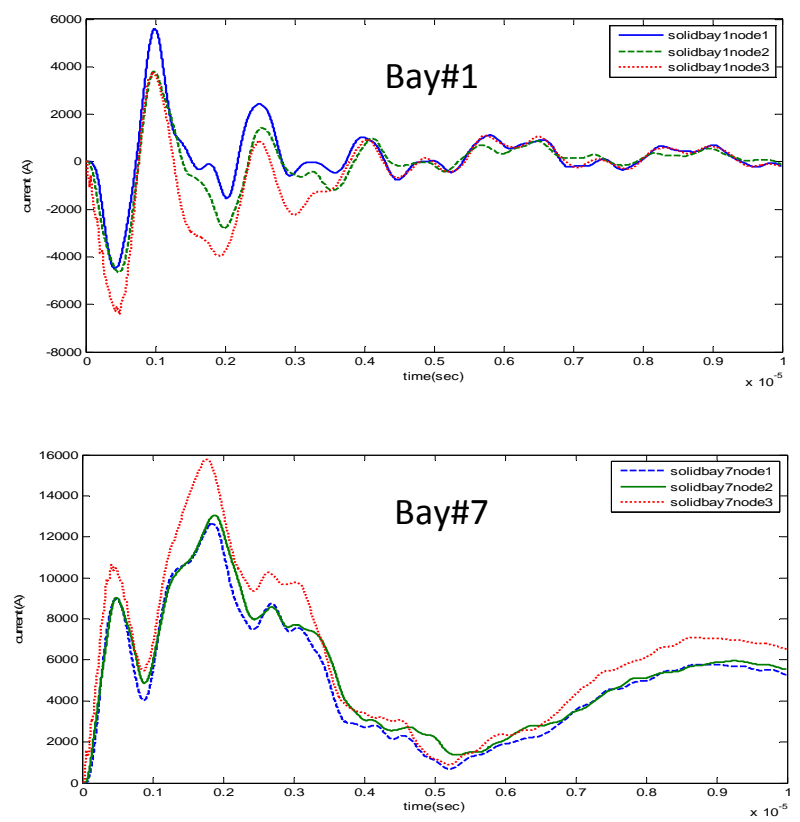

Fig. (7). Current waveforms of phase A of BB\#1 at SLG fault.
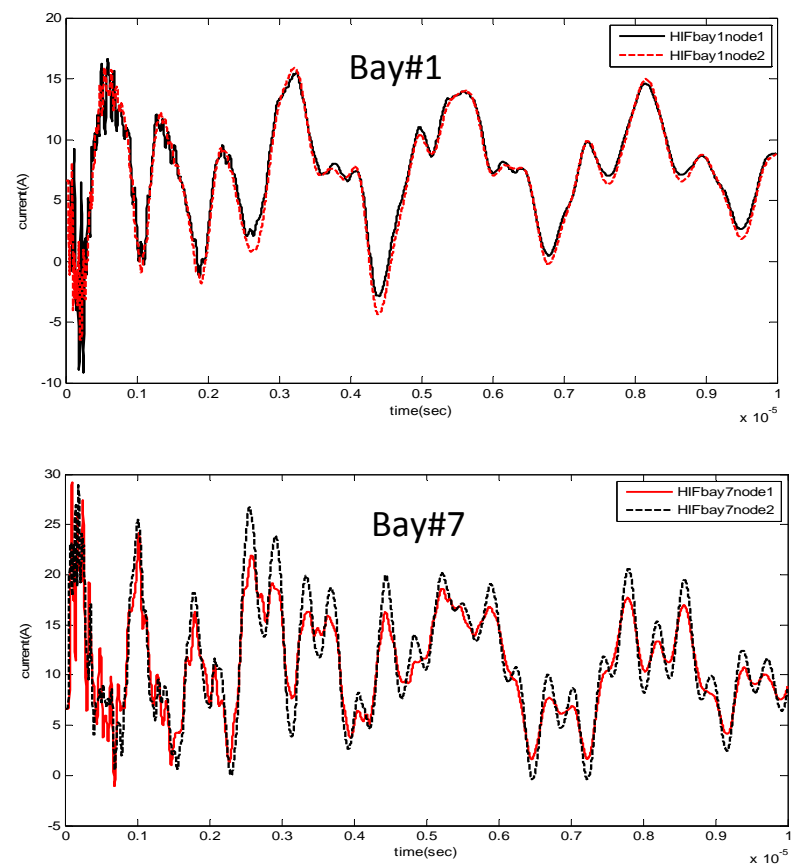

Fig. (8). Current waveforms of phase A of BB\#1 at HIF.

It is important to give meaningful training patterns, which will contain all the necessary information to generalize the problem. Special care must be taken to include boundary patterns. It is possible that a particular ANN structure with the given training data may not train properly, i.e., the training process takes too long. The structure and/or parameters must be changed and the network retrained. Also, a trained network might not perform satisfactory because of inadequate training data, or due to the structure of the network. In that case, the structure of the network should be re-designed and the process should be repeated.

After the data have been collected, there are two steps that need to be performed before the data are used to train the network: the data need to be preprocessed, and they need to be divided into subsets. It is a standard practice to normalize the inputs before applying them to the network. Generally, the normalization step is applied to both the input vectors and the target vectors in the data set. In this way, the network output always falls into a normalized range [20].

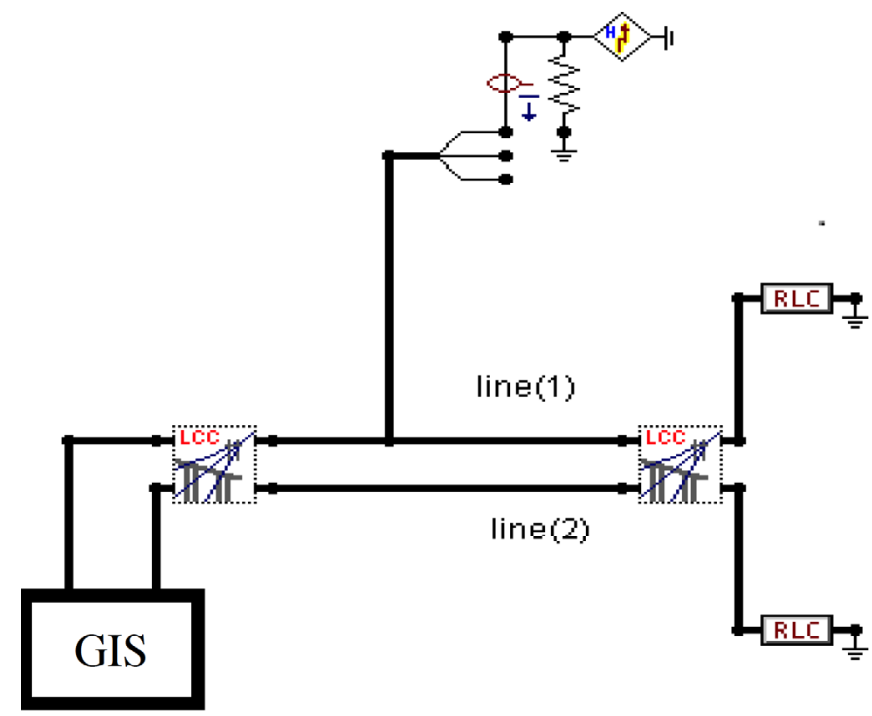

Fig. (9). ATP/EMTP Simulation of lightning in double circuit transmission lines connected to the GIS.
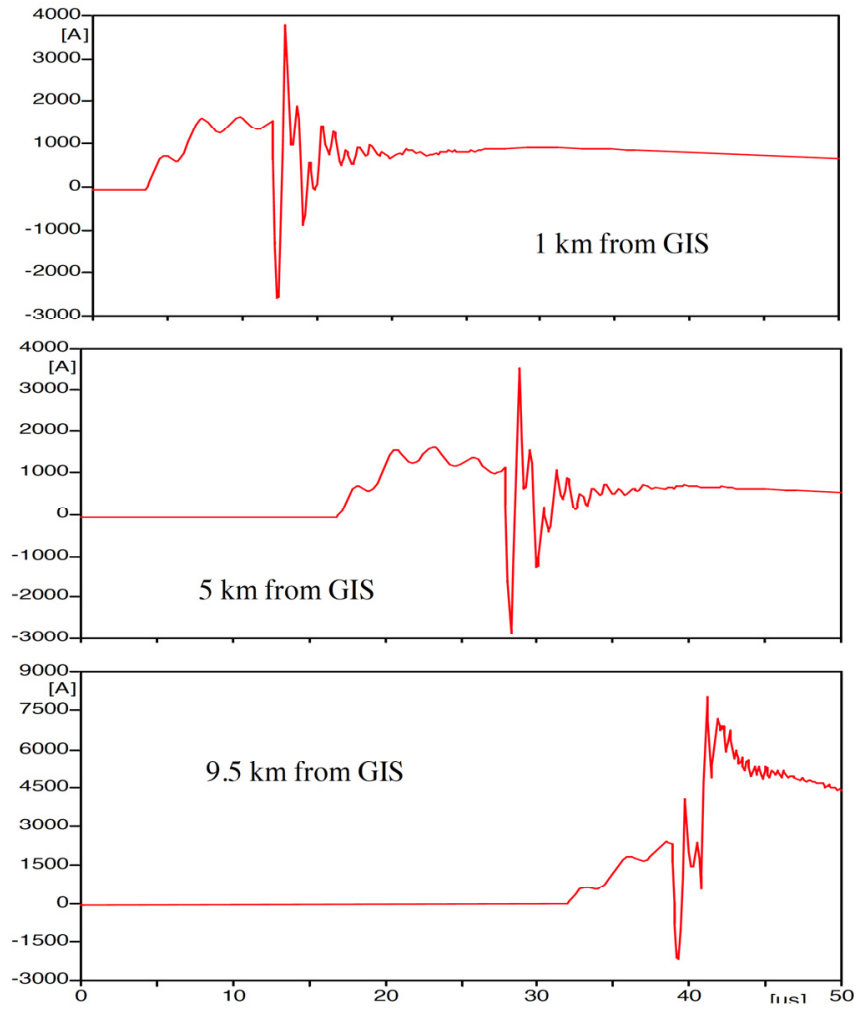

Fig. (10). Current waveforms of phase A of BB\#1 for lightning applied on Line\#1.

Multilayer feed forward network is the most widely used $[21,22]$. The back propagation algorithm is the most commonly used procedure yielding usually good generalization capabilities. Multilayer Feed forward networks consist of a series of layers. The first layer has a connection from the 
network input. Each subsequent layer has a connection from the previous layer. The final layer produces the network's output. Feed forward networks can be used for any kind of input to output. A feed forward network with hidden layer can fit any finite input-output mapping problem.
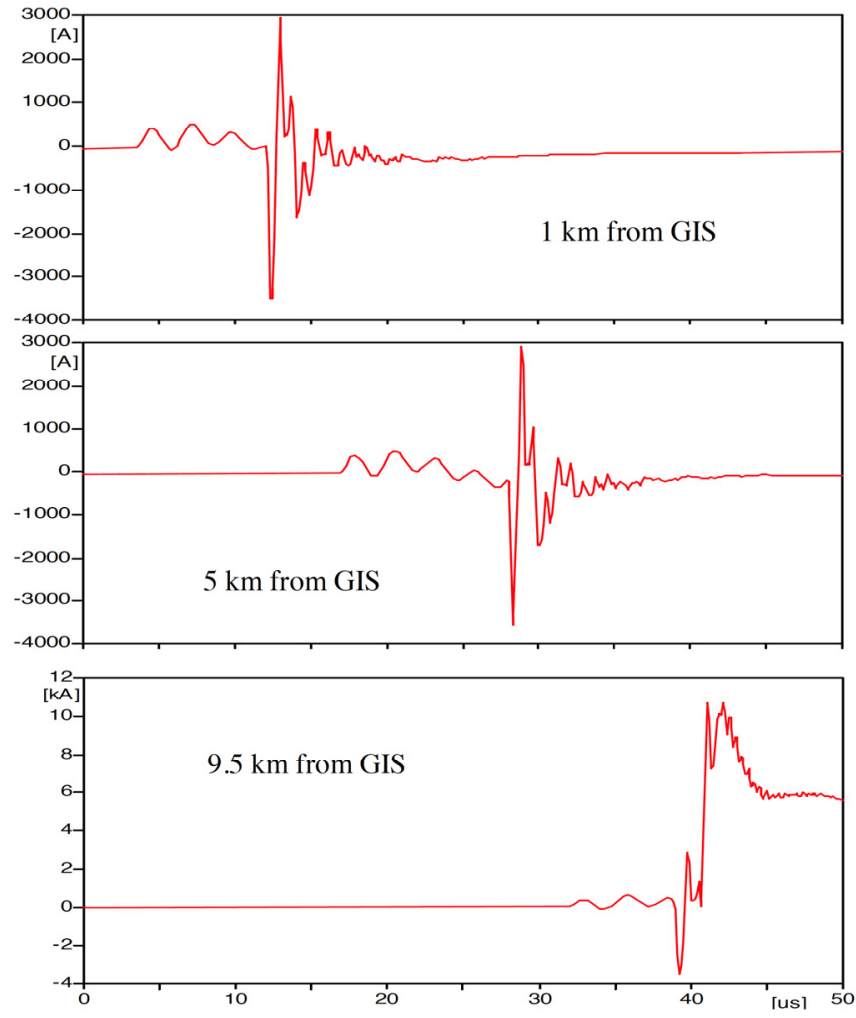

Fig. (11). Current waveforms of phase A of BB\#1 for lightning applied on Line\#2.

The back propagation learning rule is used in most applications and usually gives good generalization capabilities [5]. However; the algorithm requires long training periods and may possibly converge to local minima. Improvement techniques can be used to make back propagation more reliable and faster. The back propagation learning rule is used to adjust the weights and biases of networks to minimize the sum-squared error of the network. This is done by continually changing the values of the network weights and biases in the direction of steepest descent with respect to error. The function "scaled conjugate gradient" (Trainscg) gives best results in this work.

Various combinations of number of hidden layers and numbers of units are tested. The suitable network which gives satisfactory results is chosen. The selected network structure is shown in Fig. (12). The hidden layer is chosen to have 10 neurons. The training, validation and test performance of the proposed ANN are tested. It can be seen that the best training performance reaches 0.01 , the best testing performance is 0.06 , and the best validation performance is 0.0349 .

The second step is to identify the location. A three parallel extended ANNs are designed to do this function; one for the HIF, the second for the solidly fault to ground, and the last one for the lightning, as shown in Fig. (13).

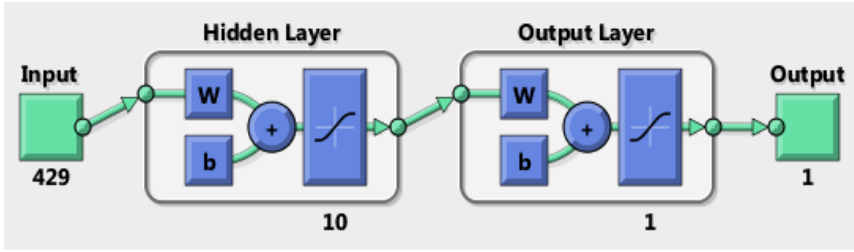

Fig. (12). The proposed neural network architecture.

Table 3. The Proposed ANN-Classifier Test Results

\begin{tabular}{|c|c|c|c|c|c|}
\hline \multicolumn{2}{|c|}{ Reason of VFT } & \multicolumn{2}{c|}{ Desired Output } & \multicolumn{2}{c|}{ Actual Outputs } \\
\hline Type & Location & Type & Location & Type & Location \\
\hline \hline SLG & Bay\#1 & 1.0 & 1.0 & 1.0003 & 1.1053 \\
\hline SLG & Bay\#2 & 1.0 & 2.0 & 1.0023 & 1.9833 \\
\hline SLG & Bay\#3 & 1.0 & 3.0 & 1.0005 & 3.0440 \\
\hline SLG & Bay\#4 & 1.0 & 4.0 & 1.0019 & 4.2000 \\
\hline SLG & Bay\#5 & 1.0 & 5.0 & 1.0010 & 5.0093 \\
\hline SLG & Bay\#6 & 1.0 & 6.0 & 1.0020 & 6.0089 \\
\hline SLG & Bay\#7 & 1.0 & 7.0 & 1.0028 & 6.9924 \\
\hline SLG & Bay\#8 & 1.0 & 8.0 & 1.0014 & 8.0055 \\
\hline HIF & Bay\#1 & 2.0 & 1.0 & 1.9316 & 0.9941 \\
\hline HIF & Bay\#2 & 2.0 & 2.0 & 1.9328 & 1.9719 \\
\hline HIF & Bay\#3 & 2.0 & 3.0 & 1.9230 & 2.8000 \\
\hline HIF & Bay\#4 & 2.0 & 4.0 & 1.9432 & 4.0049 \\
\hline HIF & Bay\#5 & 2.0 & 5.0 & 1.9347 & 4.9949 \\
\hline HIF & Bay\#6 & 2.0 & 6.0 & 1.9333 & 5.9919 \\
\hline HIF & Bay\#7 & 2.0 & 7.0 & 1.9486 & 6.9629 \\
\hline HIF & Bay\#8 & 2.0 & 8.0 & 1.9333 & 8.0053 \\
\hline Lightning & Line1 & 3.0 & 1.0 & 2.9996 & 1.0146 \\
\hline Lightning & Line1 & 3.0 & 1.0 & 2.9997 & 1.0568 \\
\hline Lightning & Line1 & 3.0 & 1.0 & 2.9999 & 1.0453 \\
\hline Lightning & Line1 & 3.0 & 1.0 & 2.9994 & 1.0687 \\
\hline Lightning & Line2 & 3.0 & 2.0 & 2.9931 & 1.9272 \\
\hline Lightning & Line2 & 3.0 & 2.0 & 2.9966 & 1.9649 \\
\hline Lightning & Line2 & 3.0 & 2.0 & 2.9993 & 1.9917 \\
\hline Lightning & Line2 & 3.0 & 2.0 & 2.9958 & 1.9769 \\
\hline
\end{tabular}

\section{TEST RESULTS}

Following the training of ANN, a separate set of the simulation results (24 inputs) is supplied to the proposed ANN in order to evaluate the validity of the proposed technique. Table 3 summarizes the test results. The left two columns of the table are the VFT type and location, respectively. Then the last two columns groups are the desired outputs and the actual outputs for VFT type and location, respectively.

It is evident from the results that, the proposed approach succeeds in detecting the VFT in any bay of the GIS. Furthermore, the proposed approach has the ability to 

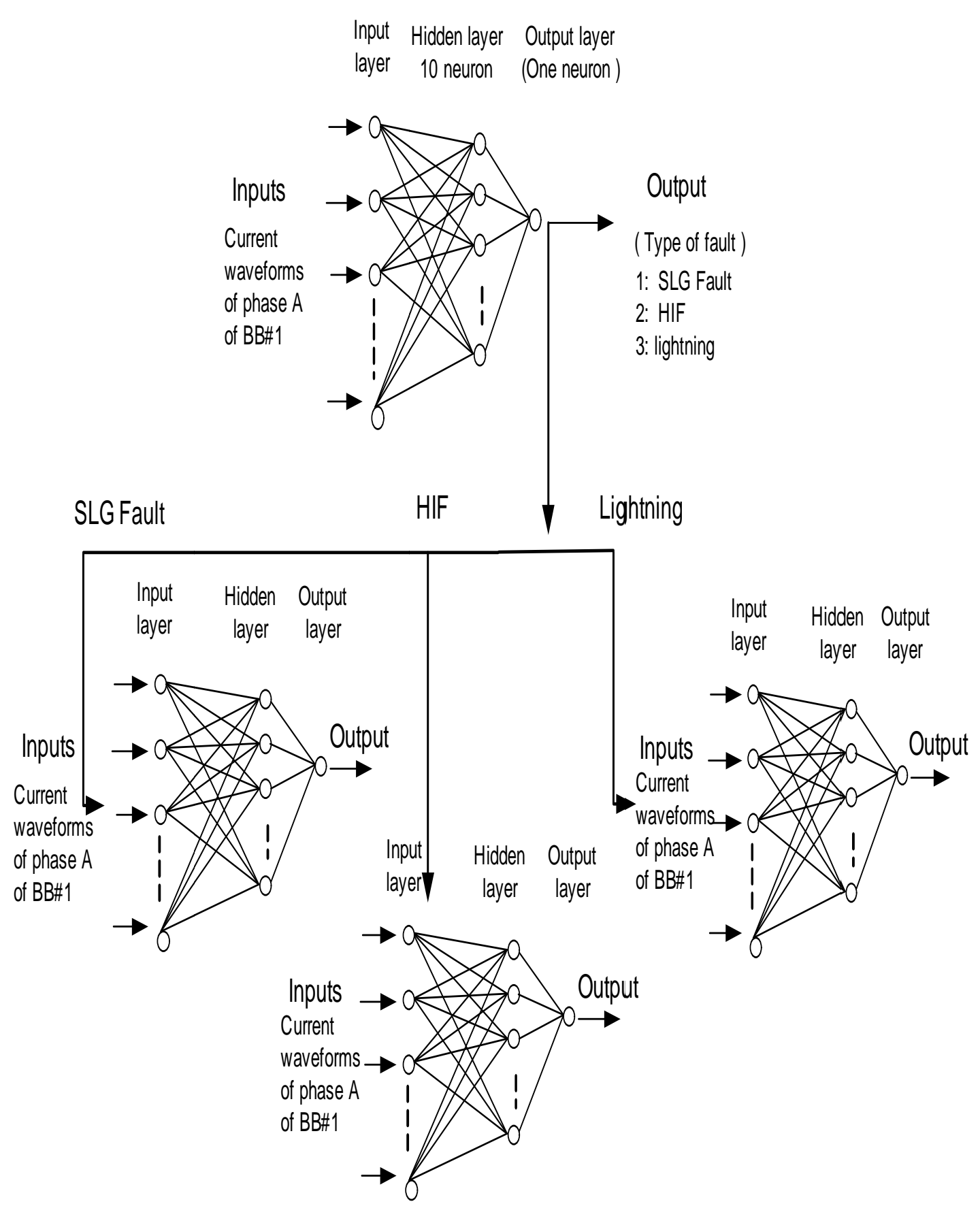

Fig. (13). Structure of the proposed multi-stage feed-forward ANN.

classify the lightning-caused VFT. The proposed approach depends on the measurement of only the current at one point in the GIS. The measurement point is selected in this study at the middle of BB\#1; between Bay\#4 and Bay\#5.

\section{CONCLUSIONS}

In this paper, an ANN-based approach is proposed and designed to detect and classify VFT in Talkha 220-kV GIS. The presented approach has the ability to detect, classify, and identify the lightning-caused VFT. The layout of the Talkha GIS is modeled using ATP/EMTP. A multi-stages ANN of multilayer feed-forward network is designed, trained, and tested. The proposed approach accurately discriminates between the bolt ground faults and the high impedance faults, and the lightning. Also, it has the ability to identify the location.

The proposed approach has distinct advantages; first of all, the high speed detection of the VFT in GIS, also, the accurate identification of the fault point or the lightningstruck line. The high speed of this approach is very important in GIS which is considered critical in the electric power network and the accurate VFT type classification leads to take the right protective actions. 


\section{ABOUT THE AUTHORS}

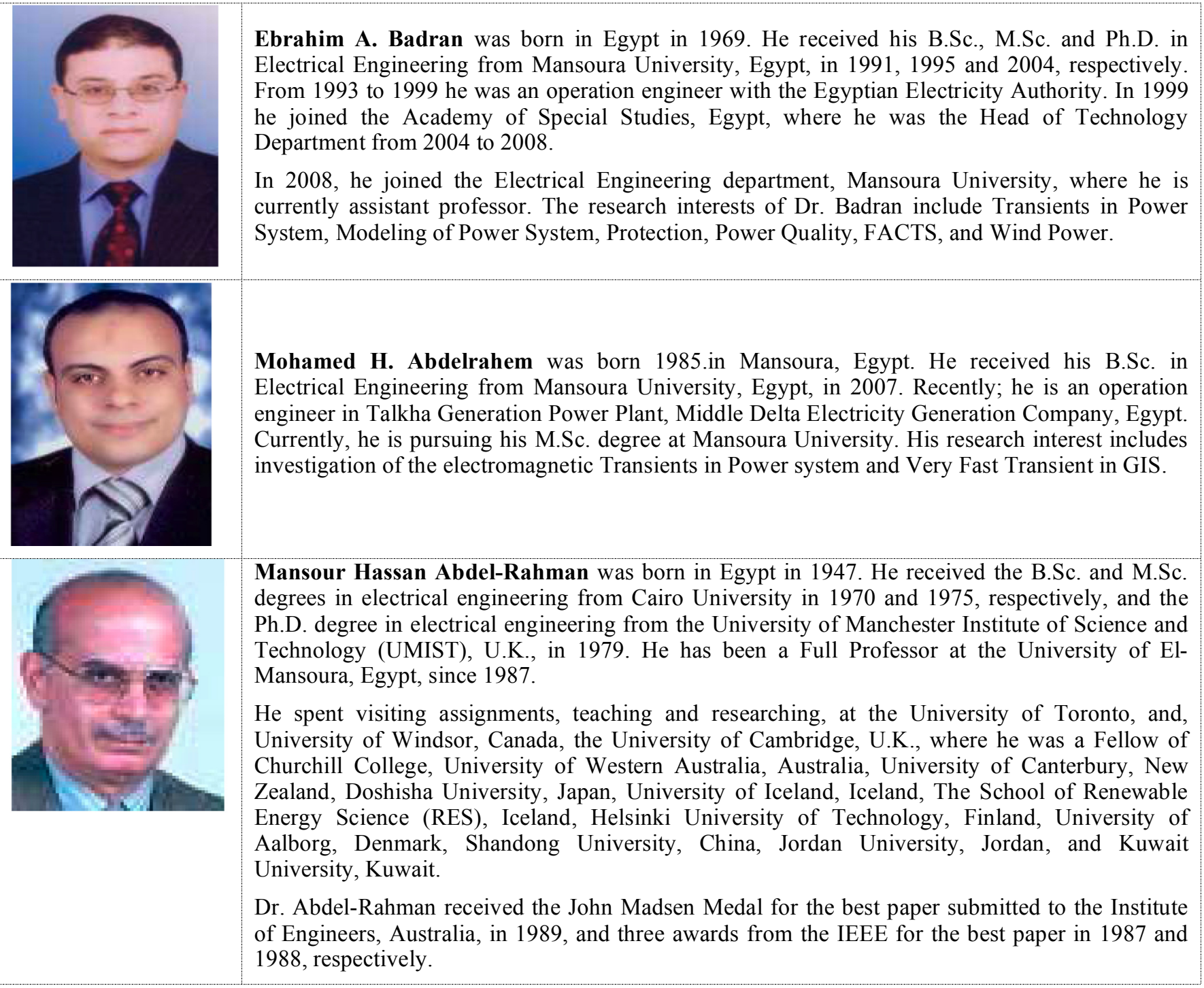

\section{CONFLICT OF INTEREST}

The authors confirm that this article content has no conflicts of interest.

\section{ACKNOWLEDGEMENTS}

Declared none.

\section{REFERENCES}

[1] Alves da silva AP, Insfran AHF, da silverira PM, Lambert-Torres G. Neural networks for fault location in substations. IEEE Trans Power Deliv 1996; 11(1): 234-8.

[2] Martinez JA, Chowdhuri P, Iravani R, Keri A, Povh D. Modeling guidelines for very fast transients in gas insulated substations. IEEE Trans Power Deliv 1996; 11(4): 2028-8.

[3] Stosur M, Szewczyk M, Piasecki W, Florkowski M, Fulczyk M. GIS disconnector switching operation - VFTO Study. MEPS Wroclaw, Poland: ABB Corporate Research Center 2010.

[4] Warwick K, Ekwue A, Aggarwal R. Artificial Intelligence Techniques in Power Systems. UK: IET 1997; pp. 302-6.

[5] Math Works ANN Toolbox for MATLAB. USA: Math Works, 2007.

[6] Aggarwal R, Song Y. Artificial neural networks in power Systems: i. General introduction to neural computing. Power Eng J 1997; 11(3): 129-6.
[7] Aggarwal R, Song Y. Artificial neural networks in power Systems: iii. Examples of applications in power systems. Power Eng J 1997; 12(6): 279-9.

[8] Kondalu M, Reddy GS, Subramanyam PS. Estimation of transient over voltages in gas insulated bus duct from $220 \mathrm{kv}$ gas Insulated substation. Int J Comp Appl 2011; 20(8): 975-13.

[9] Kho DTA, Smith KS. Analysis of very fast transient Overvoltages in a proposed $275 \mathrm{kv}$ gas insulated substation. IPST2011; 2011 June 14-17; Delft, Netherlands, 2011.

[10] Rama Rao JVG, Amarnath J, Kamakshaiah S. Simulation and Measurement of very fast transient over voltages in a $245 \mathrm{kv}$ Gis and research on suppressing method using ferrite rings. ARPN J Eng Appl Sci 2010; 5(5): 88-8.

[11] Kessel J, Atlason V, Bak CL, Lund J. Lightning simulation of a combined overhead line/cable connected gis. ICLP; $23^{\text {rd }}$ to $26^{\text {th }}$ June; Uppsala, Sweden, 2008.

[12] Pinceti P, Giannetteni M. A simplified model for $\mathrm{ZnO}$ surge arresters. IEEE Trans Power Deliv 1999; 14(2): 393-6.

[13] Peppas GD, Naxakis IA, Vitsas CT, Pyrioti EC. Surge arrester models for fast transients. ICLP; 2008 Sep 2-7; Vienna, Austria, 2008.

[14] Magro MC, Giannettoni M, Pinceti P. Validation of $\mathrm{ZnO}$ surge arresters model for overvoltage studies. IEEE Trans Power Deliv 2004; 19(4): 1692-4.

[15] Badran EA, Rizk ME, Abdel-Rahman MH. Analysis and Suppression of back-flow lightning surges in onshore wind farms. J Lightning Res 2011; 3: 1-11. 
[16] Kizilcay M. Capabilities of the transient program ATP-EMTP. EMTP Applications Laboratory 2011.

[17] Misak S. Mathematical model of electric arc respecting Mayr theory in EMTP-ATP. Acta Electrotechnica Inform 2008; 8(3): 664.

[18] Shebl KM, Badran EA, Abdalla E. A combined MODELS-TACS ATPdraw general model of the high impedance faults in distribution networks. MEPCON'10; 2010, 19-21 Dec; Cairo, Egypt 2010

[19] Schmitt H, Winter W. Simulation of lightning overvoltages in electrical power systems. IPST '01 - Rio de Janeiro, 2001 June 2428, Brazil 2001.
[20] Mazon AJ, Zamora I, Minambres JF, Zorrozua MA, Barandiaran JJ, Sagastabeitia K. A new approach to fault location in twoTerminal transmission lines using artificial neural networks. Electic Power Syst Res 2000; 56(3): 261-6.

[21] Aggarwal R, Song Y. Artificial neural networks in power Systems, ii. Types of artificial neural networks. Power Eng J 1998; 12(1): 41-7.

[22] Ukil A. Intelligent systems and signal processing in power Engineering. USA: Springer 2007.

(C) Badran et al.; Licensee Bentham Open.

This is an open access article licensed under the terms of the Creative Commons Attribution Non-Commercial License (http://creativecommons.org/licenses/by-nc/3.0/) which permits unrestricted, non-commercial use, distribution and reproduction in any medium, provided the work is properly cited. 